\title{
The effects of job crafting on subjective well-being amongst South African high school teachers
}

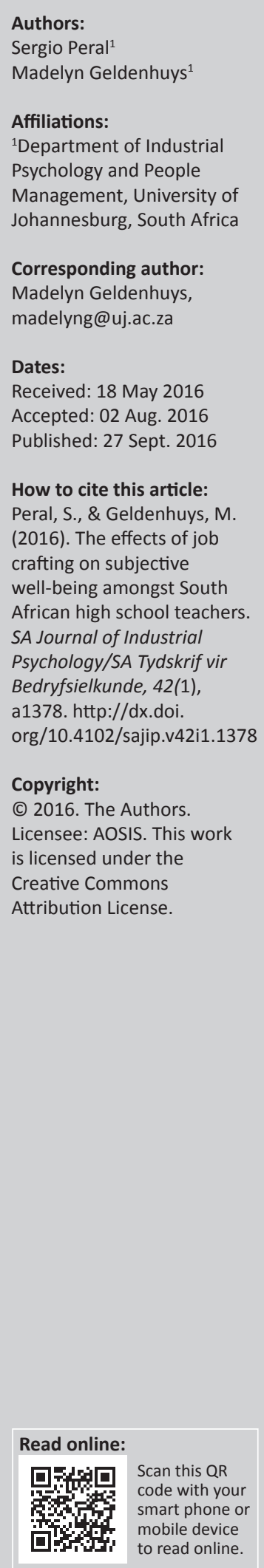

Orientation: Job crafting can result in a number of positive outcomes for teachers, such as increased meaningfulness and engagement at work. Increased work engagement and psychological meaningfulness may yield positive benefits for the practice of teaching, thus highlighting the pivotal role of job crafting.

Research purpose: The study's aim was to investigate the relationship between job crafting and subjective well-being amongst South African high school teachers. Subjective well-being comprises psychological meaningfulness and work engagement. The potential mediating effect that psychological meaningfulness had on this relationship was further explored.

Motivation for the study: Being in a highly stressful occupation, teachers need to continuously find ways to craft their working practices in order to deal effectively with their job demands and to capitalise on their available job resources. Furthermore, South Africa's current education system calls for serious proactive measures to be taken to improve and rectify the current status, such as job crafting.

Research approach, design and method: A quantitative, cross-sectional survey design was used and administered to a sample of South African high school teachers situated in Gauteng, South Africa $(N=251)$.

Main findings: A positive relationship was found between job crafting (increasing structural resources and challenging job demands) and work engagement. Furthermore, psychological meaningfulness mediated the relationship between job crafting and work engagement amongst the sampled high school teachers.

Practical/managerial implications: Teachers who craft their work to better suit their preferences and needs will obtain greater meaning in their work and experience increased levels of work engagement. Training programmes and/or group-based interventions targeted around job crafting techniques may be particularly useful in the South African teaching context.

Contribution/value-add: This study highlights the importance of job crafting to the wellbeing of teachers. It further contributes to the literature pertaining to job crafting and teaching specifically, as well as to the limited job crafting research that has been conducted in the South African context.

\section{Introduction}

Amongst all occupations, teaching remains to be one of the most highly stressful (Vazi et al., 2013). Stress and burnout are prevalent problems within the teaching profession and are recognised as a global concern (Chan, 2013). Embedded within a profession that is highly knowledge intensive, teachers often have to juggle simultaneous tasks, ranging from meeting general curriculum requirements to adapting their teaching styles to their students' unique needs (Ghitulescu, 2006). They also have to constantly learn new information and skills, keep up-to-date with technological innovations and deal with students, parents and communities (Pillay, Goddard \& Wilss, 2005). Large classroom sizes, limited decision-making latitude, students' behavioural problems, work overload and unfavourable time pressures are additional difficulties that teachers encounter in the workplace (Jackson, Rothmann \& Van de Vijver, 2006), all of which may have a negative impact on their well-being (Pretsch, Flunger, Heckmann \& Schmitt, 2013). To ensure that teachers continue to perform their pivotal roles in helping their students to grow and develop, they ought to remain physically and mentally well (Pillay et al., 2005).

Job crafting is proposed as a potential strategy that can be used to improve the well-being of South African high school teachers, as well as the overall quality of South Africa's education. Wrzesniewski and Dutton (2001) define job crafting as the process in which employees redesign or modify their 
jobs. Demerouti (2014) refers to job crafting as the manipulation of job demands and job resources initiated by employees for the purpose of making their jobs more satisfying, engaging and meaningful. With specific reference to the teaching profession, job crafting could entail the adaptation processes used in teaching practice (Ghitulescu, 2006). A recent study amongst early childhood educators reported that teachers who crafted their work, displayed increased levels of work performance, job satisfaction and commitment to their work (Leana, Appelbaum \& Shevchuk, 2009). Ghitulescu (2006) advances that teachers continuously craft their working practices in order to deal with the highly complex and demanding nature of their work.

This study concerns itself with the potential beneficial effect that job crafting has on the subjective well-being (SWB) of South African high school teachers. SWB, a term that is often used synonymously with the concept of 'happiness', is associated with various aspects of a person's subjective experience and an evaluation of the quality of their life (Keyes, Hysom \& Lupo, 2000). Teachers may experience SWB if they experience feelings of life satisfaction, satisfaction with other domains such as work and family, and if they experience frequent positive emotions (Vazi et al., 2013). Bakker and Oerlemans (2011) proclaim that positive affective states of SWB relate positively to high levels of job performance. In contrast to other positive affective states, workengagement and meaningfulness have been the most robust predictors of life satisfaction (a component of SWB) (Chan, 2013). According to Frankl (1984), meaningfulness is an antecedent to one's SWB. Finally, Basikin (2007) believes that teachers' work engagement is an essential aspect of their work, and thus grants it worthy of investigation.

\section{Research purpose and objectives}

This study contends that work engagement and psychological meaningfulness are two important factors contributing to teachers' SWB. Work engagement is defined as 'a positive, fulfilling, work-related state of mind...' (Schaufeli, Salanova, González-Romá \& Bakker, 2002, p. 74). In terms of the latter, psychological meaningfulness is defined as 'the value of a work goal or purpose, judged in relation to an individual's own ideals or standards' (May, Gilson \& Harter, 2004, p. 14). Experiences of work engagement and psychological meaningfulness have been shown to result in positive work outcomes such as increased organisational commitment (Geldenhuys, Łaba \& Venter, 2014). Bakker and Bal's (2010) study of Dutch teachers reported a positive relationship between work engagement and weekly job performance. It is thus plausible to argue that teachers who are engaged in their work and perceive their work to be meaningful are likely to display increased levels of work performance and greater commitment to their educational institutions, thus highlighting the importance of work engagement and psychological meaningfulness in teaching.

The aim of the study is to investigate the relationship between job crafting and SWB amongst South African high school teachers, where SWB is operationalised through psychological meaningfulness and work engagement. The study's aim will be achieved through the following objectives:

- to establish whether or not a relationship exists between job crafting, psychological meaningfulness and work engagement amongst teachers

- to determine whether or not psychological meaningfulness mediates the relationship between job crafting and work engagement amongst teachers.

\section{Literature review}

\section{Contextualising South Africa's education status}

Education plays a pivotal role in developing the South African economy (Jackson et al., 2006). Indeed, a good education system is crucial in creating a well-educated citizenry and maintaining socially responsive economic and political systems (Modisaotsile, 2012). According to the World Economic Forum (2014), quality education is essential for those economies wanting to move up the value chain. Regardless of its importance, South Africa's educational performance remains a grave social concern (Sosibo \& Lomlomo, 2014).

Wolhuter (2014) states that South African citizens experience heightened dissatisfaction with the education system upon the announcement of the annual matriculation examination results. Accordingly, South Africa's education system has failed to produce competent learners who display the necessary skills and knowledge to complete basic literacy and numeracy-related tasks (Department of Education, 2008). Meier (2011) further highlights the effects of a failed education system in which she states that a large number of South African first-year university students cannot read, write and comprehend to a satisfactory level. Evidently so, the 2006 Progress in International Reading Literacy Study (PIRLS) pointed out that out of 40 countries worldwide, South Africa performed the worst in terms of reading literacy levels (Mullis, Martin, Kennedy \& Foy, 2007). Raising additional concern is the fact that in 2014 the quality of South Africa's education system was ranked to be 140 out of 144 economies worldwide (World Economic Forum, 2014).

Jackson et al. (2006) believe that motivated and vigorous educators are essential to help ameliorate these conditions. Similarly, Kubberud, Helland and Smith (1999) argue that well-functioning teachers are essential for the delivery of quality education. This study proposes that job crafting can be used as an effective strategy for high school teachers to experience increased levels of SWB (work engagement and psychological meaningfulness), which could potentially result in the provision of improved quality education.

\section{Job demands-resources model}

The Job Demands-Resources (JD-R) Model postulates that job characteristics can be placed into two distinct categories, namely job demands and job resources (Bakker \& Demerouti, 2007; Tims, Bakker \& Derks, 2013). Job demands are those characteristics of a job that require sustained effort, and as a 
result, have certain physiological and psychological costs associated with them (Demerouti, Bakker, Nachreiner \& Schaufeli, 2001). The second characteristic making up a job, which stimulates personal development and is used in the process of achieving work-related goals, is referred to as job resources (Demerouti et al., 2001).

An underlying assumption of the JD-R Model is that job strain manifests when job demands out-weigh job resources. More specifically, it occurs when a person perceives their environmental (job) demands or constraints to exceed their resources or capacities (Jackson et al., 2006). Conversely, when employees have a large number of job resources at their disposal, they are subject to more positive work experiences, such as increased levels of motivation and work engagement, and as such, they are better able to combat challenging job demands (Bakker \& Demerouti, 2007; Tims et al., 2013). According to Bakker and Demerouti (2014), job resources have the potential to serve as a buffer by reducing the strain caused by excessively high job demands.

In order to understand job demands from a job crafting perspective, a distinction between challenging job demands and hindering job demands needs to be made. Challenging job demands are those aspects of a job that have the potential to promote mastery and future gain for the individual (e.g. adding tasks to their jobs and being involved in new projects) (Bakker, Rodríguez- Muñoz \& Vergel, 2015; Crawford, LePine \& Rich, 2010). Contrastingly, hindering job demands are those constraining aspects of the job that slow down progress and generally have a negative impact on the individual (e.g. role conflict and role ambiguity) (Bakker et al., 2015; Crawford et al., 2010). Challenging job demands have been shown to increase the positive impact that job resources have on work engagement (Bakker \& Demerouti, 2014). The JD-R Model serves as the foundation on which job crafting can be conceptualised.

\section{Job crafting}

As a concept, job crafting explicitly focuses on employee job redesign (Wrzesniewski \& Dutton, 2001), that is, the active process that employees engage in to shape or mould their own jobs. Unlike traditional top-down approaches, where the organisation sets forth the job structure and subsequently hires the appropriate employee to match the job specifications (Tims \& Bakker, 2010), job crafting can be viewed as a bottomup approach initiated by the employee. In particular, the employee starts to change their job to shape their work identity and to create a better fit against their personal preferences and competencies (Leana et al., 2009; Tims \& Bakker, 2010; Wrzesniewski \& Dutton, 2001).

Job crafting can be described as the change in the level of job demands and job resources initiated by employees for the purpose of making their jobs more satisfying, engaging and meaningful (Demerouti, 2014). According to Berg, Dutton and Wrzesniewski (2008), job crafting encapsulates the changes that employees actively make when designing their own jobs, in which numerous positive outcomes may present themselves, including job satisfaction, work engagement and thriving at work. More specifically, job crafting pertains to the changes that employees make to their physical, cognitive and relational boundaries (Bakker \& Demerouti, 2007; Berg et al., 2008; Tims, Bakker \& Derks, 2014).

With regard to physical boundaries, employees may engage in efforts to change the form, scope and number of tasks that they are involved in whilst working (Bakker \& Demerouti, 2007; Tims et al., 2014). For example, teachers may make structural changes to their classrooms in terms of how the desks and chairs are positioned, the tasks that are completed and the learning materials that are posted on the classroom walls. Changes in cognitive boundaries pertain to the manner in which employees view or think about their jobs (Bakker \& Demerouti, 2007; Berg et al., 2008; Tims et al., 2014). The task itself does not change, but the way in which the employee views the task changes (Tims et al., 2014), usually for the better. For example, the impact and value that a teacher believes their job has on the lives of others, in particular their pupils, may change from a pure negative and inhibiting thought to a more positive and enabling thought. Lastly, employees may craft their interpersonal relationships that they engage in during the process of performing their work (Berg et al., 2008; Tims et al., 2014). For example, mathematics teachers may choose to socialise and dominantly interact with staff belonging to the mathematics department, and may find that through this interaction, they slowly become more confident in their ability to teach mathematics. Through the process of changing any one of these job elements, employees slowly change or redesign their jobs and the social environment in which they operate (Bakker \& Demerouti, 2007), allowing employees a more engaging and meaningful work experience (Jackson et al., 2006; Wrzesniewski \& Dutton, 2001).

Demerouti (2014) asserts that regardless of the type of organisational environment in which employees finds themselves, and no matter how detailed their job descriptions are, there will always be room for them to modify (craft) their work in order to carry it out more successfully, however, a certain amount of job control is necessary. Petrou, Demerouti, Peeters, Schaufeli and Hetland (2012) view work control as a closely-related aspect to the job crafting phenomenon. Research indicates that individuals who are provided with the opportunity to take control in their workplace, are more likely to engage in job crafting behaviours (Berg et al., 2008; Frese \& Fay, 2001), which has shown to greatly influence individual and organisational performance (Berg et al., 2008).

It is important to understand that job crafting is not a single event, but rather a process in which an employee engages over a period of time (Berg et al., 2008). Organisations acknowledge that stimulating the proactive behaviours typically involved in the job crafting process is crucial to improving working conditions (Demerouti, 2014), which, given the stressful nature of their work, may be highly 
relevant to the teaching profession. Bakker, Demerouti, Hakanen and Xanthopoulou (2007) state that providing teachers with the right resources can help them to counteract the challenges of demanding work conditions.

With regard to employee health, it has been noted that job resources generally have a positive impact on employees' well-being, whereas prolonged exposure to high job demands can affect employees' levels of job strain, burnout and work engagement, and as a result can have a negative effect on their well-being (Bakker \& Demerouti, 2007; Tims et al., 2014). This study focuses exclusively on the individual, and is interested in exploring the potential impact that job crafting has on the SWB of South African high school teachers. According to Tims and Bakker (2010), a well-designed job can result in increased employee well-being. Thus, it is expected that teachers who craft their work will experience increased levels of SWB (work engagement and psychological meaningfulness).

\section{Subjective well-being}

SWB is associated with various aspects of a person's subjective experience and an evaluation of the quality of life (Diener, Sapyta \& Suh, 1998; Keyes et al., 2000). These evaluations may take the form of both cognitive judgements and affective components (Diener et al., 1998). With regard to the former, cognitive judgements entail the perception of one's expectations being met, whereas the affective component entails the degree to which emotions experienced by an individual are considered favourable (Diener et al., 1998). Diener (1984) defines SWB as a construct that consists of three distinct components, namely life satisfaction, the frequent experience of pleasant emotions (positive affect), and the relative absence of unpleasant emotions (negative affect). A teacher is said to experience SWB if they experience feelings of life satisfaction, satisfaction with other domains such as work and family, and if they are exposed to frequent positive emotions (Vazi et al., 2013).

Employees who experience SWB appear to be more productive and display more positive behaviours than employees who experience low levels of SWB (Diener, Lucas \& Oishi, 2002; Field \& Buitendach, 2011). Moreover, organisations that foster their employees' SWB have been shown to reflect better financial performance (Warr \& Clapperton, 2010). According to Dessler (1999), organisations that emphasise the development of their staff's well-being are likely to encompass a workforce with high levels of commitment. Bajorek, Gulliford and Taskila (2014) contend that well-being plays a major role in quality, productivity and performance, and may therefore have an impact on both business effectiveness and profitability.

A study conducted amongst teachers across the United States of America (USA) reported a statistically significant positive relationship between SWB and organisational performance (Ostroff, 1992). Similarly, Dewberry and Briner (2007) found a statistically significant positive relationship between staff well-being and students' educational performance. More specifically, $8 \%$ of the variance in Statutory Assessment Test (SAT) results could be attributed to teacher well-being (Dewberry \& Briner, 2007). Given the above, suffice it to say that teachers with high levels of SWB would be more effective than those with low levels of SWB. Slater, Davies and Burgess (2009) suggest that there may be a positive link between teachers' effectiveness and students' educational outcomes. In their study, it was established that pupils who had a 'good' teacher (in terms of effectiveness) displayed better examination results in comparison to pupils who had been taught by a 'poor' or 'mediocre' teacher (Slater et al., 2009).

\section{Psychological meaningfulness}

Psychological meaningfulness refers to the significance and value that a person places on his or her own existence and course of life (Taubman-Ben-Ari \& Weintroub, 2008). Hackman and Oldham (1980) refer to psychological meaningfulness as a judgement that an individual makes that compares the value of a work goal in relation to his or her own ideals, standards and values. Psychological meaningfulness is experienced when individuals perceive life to make strong emotional sense, and when life's challenges are considered worthy of energy investment and commitment (Lips-Wiersma \& Morris, 2009). Individuals experience meaningfulness when they perceive their actions to be, at minimum, useful, valuable and worthwhile (Barrick, Mount \& Li, 2013). Matuska and Christiansen (2008) state that psychological meaningfulness is essential to maintaining resilience during stressful working conditions. Thus, it is imperative for teachers to find psychological meaningfulness in their work, primarily because of the stressful nature of their work. Wolhuter, Van der Walt, Potgieter, Meyer and Mamiala (2012) found teachers to be inspired by experiences that were psychologically meaningful. Rothmann and Hamukang'andu (2013:2) state that 'psychological meaningfulness at work is an important topic in the debate about education'.

Research suggests that experienced meaningfulness is most likely one of the strongest mediators between work characteristics (i.e. job demands and job resources) and work outcomes (Barrick et al., 2013; Lips-Wiersma \& Morris, 2009). Psychological meaningfulness has shown to contribute significantly to work-related outcomes (Schueller \& Seligman, 2010), specifically work engagement (Geldenhuys et al., 2014; Olivier \& Rothmann, 2007; Rothmann \& Hamukang'andu, 2013). In their study, Geldenhuys et al. (2014) found that psychological meaningfulness predicted work engagement.

Given that people spend a proportionate amount of time at work, it is important that they find meaning in their work. Cameron, Dutton and Quinn (2003) believe that the workplace is an important context for individuals to find this meaning. Finding their work to be meaningful can result in a number of positive outcomes for employees and their employing organisations. For example, Geldenhuys et al. (2014) contend that meaningful work can result in engaged and satisfied 
employees who display greater productivity, commitment and loyalty to their organisations. Seligman (2002) further highlights the benefits of finding meaning, in which he states that meaning allows individuals to transcend, in which this transcendental experience manifests in the promotion of positive social relationships or connecting to a higher power. Frankl (1984) puts forth that meaningfulness is a contributing factor to psychological well-being, and thus values the importance of finding meaning in a person's life. In the pursuit of a good life, meaningful work is critical (Beadle \& Knight, 2012). According to Lips-Wiersma and Wright (2012), when an individual experiences their work as meaningful, it is said to be a subjective experience of the existential significance of their work.

Furthermore, meaningfulness is an important source of motivation (Frankl, 1984) and thus, it is plausible to argue that psychological meaningfulness may act as a driving motivator for teachers. Self-determination theory proposes that the motivational orientations that drive human behaviour can result in a number of benefits for individuals, including but not limited to healthy behavioural regulation and psychological well-being (Deci \& Ryan, 1985). Furthermore, the self-determined behaviour that individuals engage in has resulted in positive outcomes for the individual, such as greater persistence in behaviour and enhanced wellbeing (Deci \& Ryan, 2008; Frankl, 1984). It is important to note that psychological meaningfulness does not solely result from favourable working conditions but also from spontaneous and continuous efforts by the individual to find meaning (Isaksen, 2000). This study argues that job crafting may constitute such efforts in finding meaning.

\section{Work engagement}

Work engagement is important for individual performance (Bakker \& Demerouti, 2009). As previously mentioned, it is defined as a 'positive, fulfilling, work-related state of mind' and 'is characterized by vigor, dedication, and absorption' (Schaufeli et al., 2002, p. 74). Vigour is characterised by heightened levels of energy and mental resilience, the willingness to invest effort in one's work and the persistence that an individual displays in the face of difficult situations (Henn \& Barkhuizen, 2009; Schaufeli et al., 2002). Dedication encompasses a sense of significance, challenge, enthusiasm, inspiration and pride (Henn \& Barkhuizen, 2009; Schaufeli et al., 2002). The third dimension, namely absorption, may be regarded as an individual's feeling of being completely and happily immersed in their work to the extent that they often find it difficult to detach themselves from it (Henn \& Barkhuizen, 2009; Schaufeli et al., 2002). Individuals are considered to be engaged when they experience high levels of vigour and dedication, and elevated levels of absorption (Henn \& Barkhuizen, 2009).

Work engagement occurs when employees proactively search for motivating challenges and experiences that elicit effective problem-solving (Schaufeli, Bakker \& Salanova, 2006). Work engagement is an important indicator of employee motivation and a potential indicator of successful adaption to change (Petrou et al., 2012). Job characteristics, such as providing skill variety, task identity and feedback on results have been reported as drivers of work engagement (Saks, 2006). Rogers (2001) forwards that engaged employees produce long-term business outcomes such as improved productivity.

\section{Job crafting and subjective well-being}

In modern work contexts, job crafting is seen as a particularly critical path to meaningfulness (Wrzesniewski, Berg \& Dutton, 2010). Although little research has been conducted on the relationship between job crafting and psychological meaningfulness, there has been research that has investigated the relationship between work-role fit and psychological meaningfulness (May et al., 2004). In their study, it was concluded that work-role fit positively influences meaningfulness at work (May et al., 2004). In another study, Janik and Rothmann (2015) reported a non-significant relationship between job resources (i.e. co-worker and supervisor relationships) and psychological meaningfulness.

With regard to the second research construct, research has shown that job crafting positively influences work engagement (Bakker, Tims \& Derks, 2012; Laurence, 2010; Petrou et al., 2012; Tims et al., 2014). Work engagement may increase as a result of job crafting because employees have the potential to shape their job demands and job resources to suit their own unique preferences and needs (Tims et al., 2014). A study conducted amongst primary school teachers in the Netherlands found that work engagement amongst employees could be predicted by weekly variations in job resources (Bakker \& Bal, 2010). The study confirmed that teachers' enhanced feelings of work engagement were attributable to a resourceful working environment and led to an increase in weekly job performance. It was further suggested that engaged teachers are better able to create their own job resources (Bakker \& Bal, 2010). Bakker and Demerouti (2007) highlight that job resources, such as autonomy and social support, can mitigate the effects that high job demands have on employees, and can ultimately act as motivators in achieving improved work performance and most importantly, work engagement.

In their longitudinal study, Tims et al. (2014) used structural equation modelling (SEM) to determine whether or not employees can affect their own well-being through job crafting behaviours. Results indicated that employees who crafted their work, in particular their job resources, showed increased levels of well-being (work engagement) (Tims et al., 2014). Furthermore, they found a direct link between increasing challenging job demands and increased levels of well-being (work engagement). Bakker et al. (2015) found that individuals who crafted their structural and social job resources and challenging job demands reported increased levels of work engagement. They further found that decreasing hindering job demands was unrelated to work engagement. In a study conducted amongst educators in the 
North West Province in South Africa, Jackson et al. (2006) used SEM and found that job resources made a significant contribution to high levels of work engagement.

Based on the literature provided, the following two hypotheses are formulated:

H1: There is a positive relationship between job crafting and SWB (work engagement and psychological meaningfulness) amongst South African high school teachers.

H2: Psychological meaningfulness mediates the relationship between job crafting and work engagement amongst South African high school teachers.

\section{Research design Research approach}

A quantitative, cross-sectional research design was used to achieve the aim of this study. The participants consisted of South African high school teachers employed in both public and private high schools within Gauteng, South Africa.

\section{Research method}

\section{Research participants}

Using non-probability sampling, a sample size of 400 high school teachers was targeted. A final sample of 251 was obtained, indicative of a $63 \%$ response rate. To be eligible to participate, the following criteria had to be met: Participants needed to possess a qualification in education; they were required to have a minimum of one year's teaching experience; and they needed to be proficient in the English language. The sample comprised both men (30.3\%) and women (69.7\%), and consisted of Afrikaans (25.5\%), English (55\%), IsiZulu (6.4\%), and Sepedi (4.8\%) speaking participants. The majority of the group identified themselves as belonging to the white population $(66.5 \%)$, with the remaining participants representing the black population (31.9\%), which, according to the Employment Equity Act of 1998 (Republic of South Africa, 2014), consists of African, Indian, and mixed race individuals. With regards to employment, $64 \%$ were employed in public high schools and $33 \%$ in private high schools. Regarding highest education level obtained, $64.9 \%$ possessed a Bachelor's Degree, 25.1\% possessed an Honours Degree and 8.8\% held a Master's level qualification. The mean age and tenure of the participants was 40 and 15 years, respectively. Lastly, the sampled teachers devoted an average of 7 hours per week coaching extramural activities.

\section{Measuring instruments}

A biographical questionnaire was used in this study to assess sample-specific demographic information relating to the participants' gender, age, ethnicity, language and highest qualification obtained.

The Utrecht Work Engagement Scale (UWES-9 item) was used to assess the work engagement levels of the sampled high school teachers (Schaufeli \& Bakker, 2004). Consisting of nine items, the UWES was scored on a seven-point frequency scale ranging from 0 (never) to 6 (always). The UWES measures three dimensions of work engagement, namely vigour, dedication and absorption (Schaufeli et al., 2006). Examples of item statements include: 'I am bursting with energy every day in my work'; and 'Time flies when I am at work'. De Bruin and Henn (2013) administered the UWES-9 across 10 countries and reported mean reliability coefficients ranging between 0.85 and 0.92 , with a medium total reliability score of 0.92 . The reliability of the UWES-9 total score for this study was 0.93 , meeting the required minimum value of 0.70 (Netemeyer, Bearden \& Sharma, 2003), and as such, was adequately reliable.

The Psychological Meaningfulness Scale (PMS) (Spreitzer, 1995) was used to measure teachers' levels of psychological meaningfulness by averaging six items. A five-point Likert scale, ranging from 1 (strongly disagree) to 5 (strongly agree) was used to capture responses. The scale items measured the degree of meaning that teachers discover in their work-related activities (e.g. 'My job activities are personally meaningful to me'). Studies have demonstrated good reliability for the PMS. For example, May et al. (2004), and Olivier and Rothmann (2007) reported a Cronbach's alpha coefficient of 0.90 and 0.92, respectively. The PMS performed reliably well in this study with a reported total mean score of 0.93 .

The Job Crafting Scale (JCS) was used to assess teachers' job crafting behaviour by asking them to indicate how often they engaged in certain behaviours at work (Tims, Bakker \& Derks, 2012). The scale consisted of 21 items which measured four aspects of job crafting, namely how often employees, (1) increase their structural job resources (autonomy, variety and opportunity for development), (2) increase their social job resources (feedback, social support and coaching), (3) increase their challenging job demands and (4) decrease their hindering job demands (mental and emotional demands). Using a Likert scale ranging from 1 (never) to 5 (often), respondents indicated how often they engaged in each behaviour. Example items include: 'I make sure that I use my capacities to the fullest' and 'I decide on my own how I do things'. The coefficient alphas reported by Tims et al. (2012) for the four dimensions are increasing structural job resources $(a=0.76)$, increasing social job resources ( $a=0.73)$, increasing challenging job demands $(a=0.77)$ and decreasing hindering job demands $(a=0.75)$. The reliability scores reported in this study are increasing structural job resources $(a=0.83)$, increasing social job resources ( $a=0.83)$, increasing challenging job demands $(a=0.83)$ and decreasing hindering job demands $(a=0.84)$. The total reliability score of the JCS was 0.84 .

\section{Research procedure}

Principals and administrative staff in South African public and private high schools, within the Gauteng province, were contacted via email to invite their teachers to participate in the study. The email explained the purpose of the research and the voluntary, anonymous and confidential nature of the 
study. This approach proved inefficient and, as such, a more direct approach was deemed necessary, in which the researcher physically visited the high schools to get in contact with key informants. Once permission was granted to pursue data collection, surveys were physically distributed to all teachers in each high school. The scales were completed in paper-and-pencil format and, prior to participation, informed consent was obtained. A preface accompanied each survey which stipulated the voluntary, confidential and anonymous nature of the study as well as the purpose of the study. The contact details of the researchers were also provided in the event that participants wanted access to a summary of the results or if they had any uncertainties relating to the research study. The study was assessed by an ethics committee and ethical clearance was granted.

\section{Statistical analysis}

Statistical analyses were performed using two statistical programmes, namely $R$ version 0.98 .1103 (R Core Team, 2013) and SPSS version 22 (SPSS Inc., 2010). The Psych version 1.5.8 (Revelle, 2015), Lavaan version 0.5-20 (Yves, 2012), and Sem tools version 0.4-9 (SemTools Contributors, 2015) packages, in particular, were used. Descriptive statistics were obtained to calculate the mean, standard deviation, skewness, kurtosis, Guttmann's lambda and Cronbach's alpha for the scales utilised in the study. Upon analysis, there were no cases of excessive skewness or kurtosis, and as such, the data was considered normally distributed. SEM was performed to investigate the relationships between job crafting, work engagement and psychological meaningfulness. To investigate model fit, goodness-of-fit indices were evaluated. The weighted least squares measure of variance (WLSMV) was applied as it is a robust estimator that orders variables categorically and which deals with violations of normality (Muthén \& Muthén, 2010). It is effective and accurate in estimating confirmatory factor analysis (CFA) model parameters (Millsap \& Yun-Tein, 2004). The absolute fit indices for this study included the chi-square $\left(\chi^{2}\right)$ fit statistic, the weighted root mean residual (WRMR) and the root means square error of approximation (RMSEA). The incremental fit indices included the Tucker-Lewis Index (TLI) and the Comparative Fit Index (CFI). The chi-square difference test was applied to the competing SEM models in support of the most parsimonious model.

\section{Results}

\section{Correlational analysis}

The results of the correlational analysis are depicted in Table 1. Job crafting, as a main construct, was split into four dimensions, namely, (1) increasing structural job resources, (2) increasing social job resources, (3) increasing challenging job demands and (4) decreasing hindering job demands. Table 1 indicates that there was a significant positive correlation between work engagement and psychological meaningfulness (large effect; $r=0.76, p=0.000$ ). Similarly, there was a significant positive correlation between work engagement and increasing structural job resources (large effect; $r=0.62 ; p=0.000$ ), increasing social job resources (small effect; $r=0.25 ; p=0.000$ ) and increasing challenging job demands (large effect; $r=0.56 ; p=0.000$ ). In the same manner, there was a significant positive correlation between psychological meaningfulness and increasing structural job resources (large effect; $r=0.68 ; p=0.000$ ), increasing social job resources (small effect; $r=0.27 ; p=0.000$ ) and increasing challenging job demands (large effect; $r=0.58, p=0.000$ ).

With regards to the four job crafting dimensions, results indicate that there was a significant positive correlation between increasing structural job resources and increasing social job resources (medium effect; $r=0.48 ; p=0.000$ ), increasing challenging job demands (large effect; $r=0.92$; $p=0.000$ ) and decreasing hindering job demands (small effect; $r=0.15, p=0.021$ ). Furthermore, there was a significant positive correlation between increasing social job resources and increasing challenging job demands (medium effect; $r=0.48 ; p=0.000$ ) and decreasing hindering job demands (small effect; $r=0.21 ; p=0.002$ ). There was also a significant positive correlation between increasing challenging job demands and decreasing hindering job demands (small effect; $r=0.18 ; p=0.015$ ).

Important to note is the high correlation (0.92) between increasing structural job resources and increasing challenging job demands. This presents a case of multicollinearity, which violates the assumption for building a regression model (Pallant, 2011). Different models were therefore tested and included the combining of increasing structural job resources and increasing challenging demands.

\section{Structural equation modelling}

Step 1: Confirmatory factor analysis: CFA was used to test three different measurement models. Model 1 consisted of three latent variables, namely, (1) work engagement, (2) job crafting and (3) psychological meaningfulness. Model 1 was then compared to the hypothesised measurement model (Model 2), which consisted of six latent variables, (1) work engagement, (2) psychological meaningfulness, (3) increasing structural job resources, (4) increasing social job resources,

\begin{tabular}{|c|c|c|c|c|c|c|}
\hline Item & 1 & 2 & 3 & 4 & 5 & 6 \\
\hline 1. Work engagement & 1.00 & - & - & - & - & - \\
\hline 2. Psychological meaningfulness & $0.76 *$ & 1.00 & - & - & - & - \\
\hline 3. Job crafting (Increasing structural job resources) & $0.62 *$ & $0.68 *$ & 1.00 & - & - & - \\
\hline 4. Job crafting (Increasing social job resources) & $0.25 *$ & $0.27 *$ & $0.48 *$ & 1.00 & - & - \\
\hline 5. Job crafting (Increasing challenging job demands) & $0.56^{*}$ & $0.58^{*}$ & $0.92 *$ & $0.48 *$ & 1.00 & - \\
\hline 6. Job crafting (Decreasing hindering job demands) & -0.06 & -0.04 & $0.15 *$ & $0.21 *$ & $0.18^{*}$ & 1.00 \\
\hline
\end{tabular}

$*, p<0.05$. 
(5) increasing challenging job demands and (6) decreasing hindering job demands. Lastly, Model 3 was constructed and termed 'subjective well-being'. Model 3 consisted of one latent variable or general factor, which comprised 36 observed items.

During the CFA, item 7 of the JCS was removed ('I decide on my own how I do things') because of its undesirably low factor loading of 0.14 on the scale. The factor loadings produced by the scale items, for each of their respective latent variables, ranged from 0.50 to 0.90 . Furthermore, each latent variable and its observed items indicated a statistically significant relationship ( $p<0.05)$. Table 2 presents the goodness-of-fit indices for the three competing measurement models.

Inspection of the chi-square test as a fit statistic for Model 1 $(p<0.000)$, Model $2(p<0.000)$ and Model $3(p<0.000)$ indicated that none of the models produced a perfect fit. Fortunately, alternative fit statistics were used. Based on the remaining fit statistics, the hypothesised model (Model 2) fit the data best. The fit statistics of the four fit indices were acceptable: $\mathrm{TLI}=0.96, \mathrm{CFI}=0.96, \mathrm{RMSEA}=0.06$ and $\mathrm{WRMR}=1.16$. The chi-square difference test $\left(\chi^{2}=-1769.674 ; d f=-7 ; p<0.00\right)$ between Model 1 and Model 2 revealed that Model 2 has the best fit.

\section{Reliability of the hypothesised measurement model}

The reliability of the hypothesised measurement model (Model 2) and its individual components were evaluated by examining McDonald's omega coefficient (McDonald, 1999). The omega coefficient values ranged from 0.76 to 0.97 for each of the variables in the model, indicative of good acceptable reliability. The total reliability of the model was reported as 0.97 .

Step 2: Testing the structural model: The CFA indicated that the hypothesised measurement model (Model 2) was the most parsimonious model, and as such, was submitted for further analysis. Five structural models were tested and compared in the second step of the analysis. Given that Model 2 was submitted for further analysis, the five structural models were consequently labelled 'Model 2a, 2b, 2c, 2d and 2e respectively. Model 2a comprised six latent variables, namely work engagement, psychological meaningfulness, increasing structural job resources, increasing social job resources, increasing challenging job demands and decreasing hindering job demands. To account for the issue of multicollinearity, adjustments were made to Model 2b.

Model $2 \mathrm{~b}$ consisted of five latent variables namely, work engagement, psychological meaningfulness, increasing

TABLE 2: Goodness-of-fit indices for the three competing measurement models.

\begin{tabular}{lccccccc}
\hline Model & $\mathbf{x}^{2}$ & $\boldsymbol{p}$ & $\boldsymbol{d} \boldsymbol{f}$ & TLI & CFI & RMSEA & WRMR \\
\hline Model 1 & 2090.56 & 0.000 & 557 & 0.865 & 0.874 & 0.110 & 1.944 \\
Model 2 & 979.35 & 0.000 & 545 & 0.961 & 0.964 & 0.059 & 1.160 \\
Model 3 & 3186.04 & 0.000 & 560 & 0.770 & 0.784 & 0.143 & 2.486
\end{tabular}

$x^{2}$, chi-square; $d f$, degrees of freedom; TLI, Tucker-Lewis Index; CFI, comparative fit index; RMSEA root mean square error of approximation; WRMR, weighted root mean square residual. structural job resources, increasing social job resources and decreasing hindering job demands. 'Increasing challenging job demands' was removed because it produced a substantially high correlation in the early stages of analysis. Model 2c, which was termed the 'resources' model, comprised of four latent variables, namely, work engagement, psychological meaningfulness, increasing structural job resources and increasing social job resources. This model excluded the two job demands dimensions (i.e. increasing challenging job demands and decreasing hindering job demands) of the job crafting construct.

In a similar fashion, Model $2 \mathrm{~d}$ was constructed and labelled the 'demands' model. Comprised of four latent variables, Model 2d excluded the job resources dimensions from the job crafting variable, namely, increasing structural job resources and increasing social job resources. Lastly, Model 2e was created and compared to the previous four competing structural models.

Model 2e, the new hypothesised structural model, combined the job crafting dimensions that were highly correlated (i.e. increasing structural job resources and increasing challenging job demands) to form one latent variable, which was termed 'increasing development-based resources'. Model 2e consisted of five latent variables, namely work engagement, psychological meaningfulness, increasing development-based resources, increasing social job resources, and decreasing hindering job demands. The fit statistics of the various competing structural models are presented in Table 3 . The chi-square difference test $\left(\chi^{2}=273.393 ; d f=-160 ; p<0.00\right)$ between Model $2 \mathrm{~b}$ and Model $2 \mathrm{e}$ revealed that Model 2e has the best fit.

\section{Direct and indirect effects}

In order to investigate the direct effect that job crafting had on both work engagement and psychological meaningfulness, a standard multiple regression was performed. According to Pallant (2011), standard multiple regression is the most commonly used multiple regression analysis and entails evaluating the predictive power (variance) of each independent variable in the model. The regression involved two steps. In Step 1, work engagement was entered as the dependent variable and psychological meaningfulness, and job crafting as the independent variables. In Step 2, psychological meaningfulness was entered as the dependent variable and job crafting as the independent variable. Through the execution of Step 1 and Step 2, the relationships between the variables were explored. The results of the standard multiple regression can be seen in Table 4.

TABLE 3: Fit statistics for the five competing structural models.

\begin{tabular}{lccccccc}
\hline Model & $\mathbf{x}^{\mathbf{2}}$ & $\boldsymbol{p}$ & $\boldsymbol{d} \boldsymbol{f}$ & CFI & TLI & RMSEA & WRMR \\
\hline Model 2a & 979.346 & 0.000 & 545 & 0.964 & 0.961 & 0.059 & 1.160 \\
Model 2b & 757.216 & 0.000 & 395 & 0.969 & 0.966 & 0.063 & 1.154 \\
Model 2c & 741.10 & 0.000 & 367 & 0.969 & 0.965 & 0.066 & 1.104 \\
Model 2d & 630.847 & 0.000 & 293 & 0.970 & 0.966 & 0.070 & 1.176 \\
Model 2e & 984.510 & 0.000 & 550 & 0.964 & 0.961 & 0.059 & 1.170 \\
\hline
\end{tabular}

$x^{2}$, chi-square; $d f$, degrees of freedom; TLI, Tucker-Lewis Index; CFI, comparative fit index; RMSEA, root mean square error of approximation. 
TABLE 4: Standardised regression coefficients of the latent variables (new hypothesised model).

\begin{tabular}{|c|c|c|c|c|c|c|}
\hline Context & Variable & Standardised beta & Estimate & SE & Est/SE & $p$ \\
\hline \multirow[t]{4}{*}{ Work engagement } & Psychological meaningfulness & 0.61 & 0.72 & 0.07 & 10.14 & $0.000 * *$ \\
\hline & Increasing development-based job resources & 0.23 & 0.36 & 0.10 & 3.60 & $0.001 * *$ \\
\hline & Increasing social job resources & -0.01 & -0.02 & 0.10 & -0.20 & 0.805 \\
\hline & Decreasing hindering job demands & -0.07 & -0.12 & 0.07 & -1.71 & 0.111 \\
\hline \multirow[t]{2}{*}{ Psychological meaningfulness } & Increasing developmental-based job resources & 0.71 & 0.94 & 0.10 & 9.4 & $0.000 * *$ \\
\hline & Increasing social job resources & -0.05 & -0.06 & 0.09 & -0.67 & 0.526 \\
\hline
\end{tabular}

$\mathrm{SE}$, standard error; Est/SE, estimate divided by standard error; $p$, obtained significance value.

$*, p<0.05 ; * *, p<0.001$.

TABLE 5: The indirect effect of job crafting on work engagement via psychological meaningfulness.

\begin{tabular}{lcc}
\hline Variable & Unstandardised estimate & Standardised estimate \\
\hline PM (increasing development-based resources) & 0.69 & 0.43 \\
PM (decreasing hindering job demands) & -0.14 & -0.09 \\
\hline
\end{tabular}

$*, p<0.05 ; * *, p<0.001 ; 95 \% \mathrm{BC} \mathrm{Cl}, 95 \%$ bias-corrected confidence interval; LLCI, lower limit of confidence interval; ULCI, upper limit of confidence interval.

Upon observation of the $p$ values for each independent variable in Step 1 of the regression, it is evident that psychological meaningfulness $(p=0.000)$ and job crafting (increasing development-based job resources) $(p=0.001)$ made a statistically significant, unique contribution in predicting work engagement. That is, a standard deviation increase in psychological meaningfulness will lead to a 0.61 standard deviation increase in work engagement. In terms of the latter, a standard deviation increase in 'increasing developmental-based job resources' will result in a 0.23 standard deviation increase in work engagement. Increasing social resources and decreasing hindering job demands made no significant contribution in predicting work engagement.

With regard to Step 2 of the regression, it is apparent that 'increasing development-based job resources' and 'decreasing hindering job demands' made a statistically significant unique contribution in predicting psychological meaningfulness. A standard deviation increase in 'increasing developmentbased job resources' will result in a 0.71 standard deviation increase in psychological meaningfulness. Furthermore, a standard deviation increase in 'decreasing hindering job demands' will result in a 0.14 standard deviation decrease in psychological meaningfulness. Increasing social job resources made no significant contribution in predicting psychological meaningfulness.

\section{The mediating effect of psychological meaningfulness on job crafting and work engagement}

To determine the mediating effect that psychological meaningfulness had on the relationship between job crafting and work engagement, indirect effects were tested. For the purpose of the study, job crafting served as the independent variable, whereas work engagement and psychological meaningfulness served as the dependent variable and mediating variable, respectively.

Figure 1 shows the indirect effects of job crafting on work engagement via psychological meaningfulness. The 95\% confidence intervals of psychological meaningfulness did not include zero. Therefore, increasing development-based

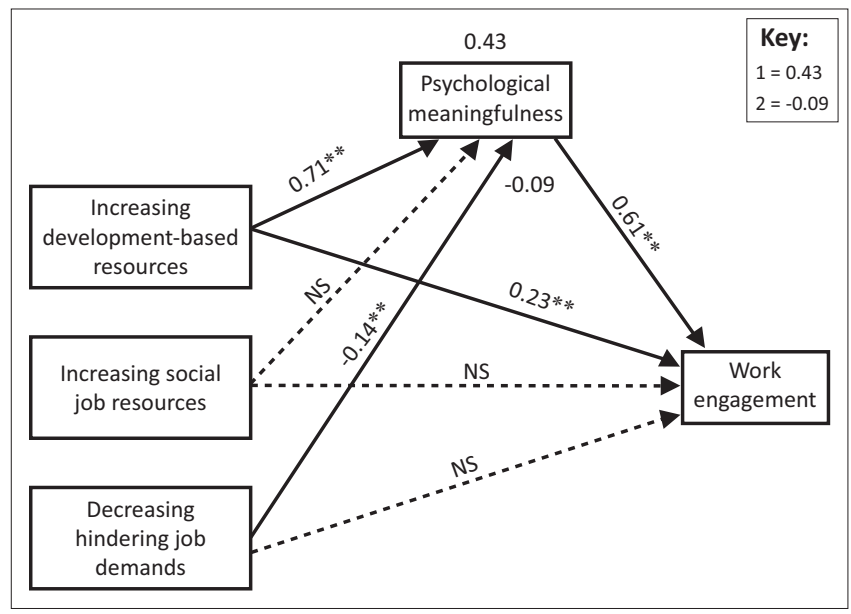

$* *, p<0.05$.

NS, non-significance; 1 , partial mediation of psychological meaningfulness on increasing development-based job resource and work engagement; 2 , full mediation of psychological meaningfulness on decreasing hindering job demands and work engagement.

FIGURE 1: Structural model depicting the relationship between job crafting, work engagement and psychological meaningfulness.

resources as well as decreasing hindering job demands had an indirect effect on work engagement via psychological meaningfulness. The results indicate that psychological meaningfulness had a partial mediation on the relationship between 'increasing development-based resources' and work engagement with a value of 0.43 . In terms of the latter, psychological meaningfulness fully mediated the relationship between 'decreasing hindering job demands' and work engagement with a value of -0.09 .

\section{Discussion}

\section{Interpretation of findings}

The study's aim was to investigate the relationship between job crafting and SWB amongst South African high school teachers. The two constructs that were explored, and which comprised a teacher's SWB, were psychological meaningfulness and work engagement. SEM was used as the primary statistical technique to achieve the study's objectives.

The scales used in the study were all reliable (Netemeyer et al., 2003). This is consistent with previous research findings 
(De Bruin \& Henn, 2013; May et al., 2004; Olivier \& Rothmann, 2007; Tims et al., 2012). Results obtained from the correlational analysis indicated that a relationship did indeed exist between job crafting, psychological meaningfulness and work engagement amongst teachers, providing acceptance for hypothesis 1 (H1). With regard to hypothesis 2 (H2), which stated that psychological meaningfulness mediated the relationship between job crafting and work engagement, SEM showed that psychological meaningfulness did indeed mediate this relationship, and as such, hypothesis 2 (H2) was accepted. A detailed coverage of the findings is presented below.

\section{The effect of job crafting on SWB amongst South African high school teachers}

To investigate the effect that job crafting had on teachers' SWB (i.e. psychological meaningfulness and work engagement), SEM was performed. The SEM consisted of two components, namely a measurement model (essentially the CFA) and a structural model (Schreiber, Stage, King, Nora \& Barlow, 2006). Results obtained from the CFA (Step 1) suggested that the hypothesised measurement model (Model 2) was the most parsimonious. Model 2 consisted of six latent variables, namely, work engagement, psychological meaningfulness, increasing structural job resources, increasing social job resources, increasing challenging job demands and decreasing hindering job demands. The second step of the analysis involved the structural model component and aimed to assess the interrelationships between the main research constructs. The findings are discussed below.

\section{Increasing development-based job resources}

Four aspects of job crafting are typically measured, namely how often employees, (1) increase their structural job resources, (2) increase their social job resources, (3) increase their challenging job demands and (4) decrease their hindering job demands (Tims et al., 2012). However, in this study, an exceptionally high correlation (0.92) was found between 'increasing structural job resources' and 'increasing challenging job demands'. This may partly be because the beneficial outcomes produced by engaging in these two forms of job crafting behaviours are indeed the same, and thus, the distinction between the two may become blurred. For example, Tims et al. (2013) state that job resources stimulate personal development and that challenging job demands lead to personal gain or growth, which is one and the same. A study that they conducted concluded that job resources and challenging job demands both lead to increased levels in well-being (Tims et al., 2013). Suffice it to say then, that challenging job demands are indeed resourceful, and as such, may not necessarily be seen by teachers as a job demand, but rather as a job resource. Given that these two aspects of job crafting result in personal growth and development, the researcher collapsed the two dimensions to form one dimension, termed 'development-based job resources'.

SEM results indicated that increasing development-based job resources (structural job resources and challenging job demands) had a direct effect on work engagement. Teachers who crafted their work by increasing their development-based job resources experienced increased levels of work engagement. This finding is echoed in previous research conducted amongst teachers (Bakker \& Bal, 2010; Jackson et al., 2006), and parallel to research conducted in various other organisational contexts (Bakker \& Demerouti, 2007; Bakker, et al., 2015; Tims et al., 2014).

With regard to psychological meaningfulness, it was established that increasing development-based job resources had a direct effect on psychological meaningfulness, which indicates that teachers who crafted their work (in terms of increasing development-based job resources) experienced increased psychological meaningfulness. In support of this finding, Bakker and Demerouti (2007) contend that job resources have a positive impact on employee well-being, and given that psychological meaningfulness contributes to a teacher's SWB, this finding is validated. Experienced meaningfulness may well be one of the strongest mediators between work characteristics and work outcomes (Barrick et al., 2013; Lips-Wiersma \& Morris, 2009; Schueller \& Seligman, 2010). The results indicated that psychological meaningfulness partially mediated the relationship between job crafting (increasing development-based resources) and work engagement. Specifically, increasing development-based job resources had an indirect effect on work engagement via psychological meaningfulness. This implies that teachers who crafted their work, through increasing their developmentbased job resources, experienced increased psychological meaningfulness, consequently resulting in increased levels of work engagement. Research has found that psychological meaningfulness strongly contributes to work-related outcomes such as work engagement (Geldenhuys et al., 2014; Olivier \& Rothmann, 2007; Rothmann \& Hamukang'andu, 2013).

\section{Increasing social job resources}

Crafting one's work through increasing social job resources involves employees actively seeking inter alia performance feedback, coaching and social support (Bakker et al., 2015; Tims et al.,2012). Broadly speaking, it refers to the changes in relational boundaries that employees make, whereby they craft their interpersonal relationships that they engage in whilst working (Berg et al., 2008). The results showed that increasing social job resources had no effect on work engagement and psychological meaningfulness amongst the sampled teachers. That is, teachers who crafted their work, through increasing their social job resources, displayed no signs of increased psychological meaningfulness or work engagement. In a similar fashion, Janik and Rothmann (2015) reported a non-significant relationship between social job resources (i.e. co-worker and supervisor relationships) and psychological meaningfulness. However, by contrast Bakker et al. (2015) found that crafting one's work, through increasing their social job resources, was positively related to work engagement. The latter finding did not pertain to the teaching profession however.

A potential explanation for this finding is that the majority of a teacher's interaction is spent with their pupils as opposed to their colleagues, and perhaps the limited time 
that teachers do spend with their co-workers contributes little to their levels of psychological meaningfulness and work engagement. Additionally, teachers may find that they cherish the relationships that they have with their students more than their relationships with their colleagues. A final explanation to this finding, and that which addresses the job crafting dimension directly, is that teachers may not receive continuous social support, coaching or feedback on their performance, which could explain why there is no influence on their levels of psychological meaningfulness and work engagement.

\section{Decreasing hindering job demands}

Job demands refer to those work characteristics that require sustained effort and that have certain costs associated with them (Tims et al., 2013). Prolonged exposure to job demands has a negative impact on work engagement and overall employee well-being (Bakker \& Demerouti, 2007; Tims et al., 2013). The results yielded somewhat of an unexpected finding, namely that decreasing hindering job demands had no effect on teachers' level of work engagement. That is, teachers who attempted to craft their work by decreasing their hindering job demands experienced no increase in their levels of work engagement. Bakker et al. (2015) also found that crafting one's work by decreasing hindering job demands had no impact on work engagement. Upon analysis of the descriptive statistics, it was found that the sampled high school teachers seldom took action in an effort to decrease their hindering job demands, thus providing a plausible explanation to this peculiar finding.

In terms of the second research construct explored, namely psychological meaningfulness, results indicated that decreasing hindering job demands had a direct negative effect on teachers' levels of psychological meaningfulness. This implies that teachers who crafted their work by decreasing their hindering job demands experienced a decrease in their levels of psychological meaningfulness. This could partly be attributed to the fact that engaging in efforts to decrease one's hindering job demands is somewhat of a taxing experience, which may not facilitate the provision of meaning in the teaching context.

\section{Research implications and value add}

This study is considered practically important for the teaching profession and for fellow researchers. The empirical findings obtained from the present study demonstrate that job crafting may be used as an effective strategy for teachers, particularly in the South African context. Teachers who are given the opportunity to craft their working practices may experience increased SWB (i.e. psychological meaningfulness and work engagement), potentially leading to a number of positive organisational outcomes. Furthermore, the study extends job crafting research and contributes to the dearth of job crafting literature specifically pertaining to the teaching profession. It also raises attention amongst policymakers to consider the importance of job crafting, psychological meaningfulness and work engagement in the South African teaching context.

\section{Limitations}

Whilst the study showed that job crafting results in positive outcomes for teachers, it had some limitations. The small sample size means that the findings may not be generalised to the larger population. Furthermore, the sample consisted of high school teachers that resided solely within the Gauteng province. As the study was not longitudinal, it is not possible to assign causality. Furthermore, the self-reporting nature of the research design (i.e. quantitative survey) may be subject to social-response bias.

\section{Recommendations for future research}

To enhance the generalisability of the findings, a larger sample size should be considered. It is recommended that research be conducted on high school teachers throughout the nine provinces in South Africa and not solely the Gauteng region. With regard to the cross-sectional nature of the study, it is recommended that a longitudinal research study be carried out to determine the existence of a possible causal relationship between job crafting and SWB amongst South African high school teachers. To address the issue of selfreporting bias, it is suggested that a test-retest administration be conducted. Finally, given that 'increasing social job resources' and 'decreasing hindering job demands' had no impact on teachers' work engagement, researchers are encouraged to explore the potential reasons behind this matter. This could potentially be achieved through the use of a qualitative or mixed-method research approach.

\section{Conclusion}

The study's aim was to investigate the relationship between job crafting and SWB (psychological meaningfulness and work engagement) amongst South African high school teachers. The findings indicated that a positive relationship did indeed exist, thus providing support for the importance of job crafting in the teaching profession. Considering the quality of South Africa's current education, job crafting may be viewed as a potential strategy that teachers and their employing organisations can use to improve the overall effectiveness and quality of education in South Africa.

\section{Acknowledgements Competing interests}

The authors declare that they have no financial or personal relationships which may have inappropriately influenced them in writing this article.

\section{Authors' contributions}

This research was done within the scope of a project on positive organisational behaviour with M.G. acting as the project leader and supervisor and S.L.P. conducting the research. 


\section{References}

Bajorek, Z., Gulliford, J., \& Taskila, T. (2014). Healthy teachers, higher marks? Establishing a link between teacher health \& wellbeing, and student outcomes. Lancaster, UK: The Work Foundation, Lancaster University.

Bakker, A.B., \& Bal, M.P. (2010). Weekly work engagement and performance: A study among starting teachers. Journal of Occupational and Organizational Psychology, 83(1), 189-206. http://dx.doi.org/10.1348/096317909X402596

Bakker, A.B., \& Demerouti, E. (2007). The job demands-resources model: State of the art. Journal of Managerial Psychology, 22(3), 309-328. http://dx.doi. org/10.1108/02683940710733115

Bakker, A. B., \& Demerouti, E. (2009). The crossover of work engagement between working couples: A closer look at the role of empathy. Journal of Managerial Psychology, 24, 220-236.

Bakker, A.B., \& Demerouti, E. (2014). Job demands-resources theory. In C. Cooper \& P. Chen (Eds.), Wellbeing: A complete reference guide (pp. 37-64). Chichester, UK: Wiley-Blackwell.

Bakker, A.B., Hakanen, J.J., Demerouti, E., \& Xanthopoulou, D. (2007). Job resources boost work engagement, particularly when job demands are high. Journal of Educational Psychology, 99(2), 274. http://dx.doi.org/10.1037/0022-0663.99. 2.274

Bakker, A.B., \& Oerlemans, W. (2011). Subjective well-being in organizations. In K.S Cameron \& G.M. Spreitzer (Eds.), The Oxford handbook of positive organizational scholarship (pp. 178-189). New York: Oxford University Press.

Bakker, A.B., Rodríguez-Muñoz, A., \& Vergel, A.I.S. (2015). Modelling job crafting behaviours: Implications for work engagement. Human Relations, 69(1), 169-189. http://dx.doi.org/10.1177/0018726715581690

Bakker, A.B., Tims, M., \& Derks, D. (2012). Proactive personality and performance: The role of job crafting and work engagement. Human Relations, 65(10), 1359-1378. http://dx.doi.org/10.1177/0018726712453471

Barrick, M.R., Mount, M.K., \& Li, N. (2013). The theory of purposeful work behavior: The role of personality, higher-order goals, and job characteristics. Academy of
Management Review, 38(1), 132-153. http://dx.doi.org/10.5465/amr.2010.0479

Basikin, B. (2007). Vigor, dedication and absorption: Work engagement among secondary school English teachers in Indonesia. Paper presented at the annual AARE Conference, 25-29 November, 2007, Perth, Western Australia. Retrieved May 26, 2015, from http://eprints.uny.ac.id/1071

Beadle, R., \& Knight, K. (2012). Virtue and Meaningful Work. Business Ethics Quarterly, 22(2), 433-450. http://dx.doi.org/10.5840/beq201222219

Berg, J.M., Dutton, J.E., \& Wrzesniewski, A. (2008). What is job crafting and why does it matter? Theory-to-practice briefing. Ann Arbor, Ml: Center for Positive Organizational Scholarship, Michigan Ross School of Business. Retrieved May 26 2015, from http://www.bus.umich.edu/Positive/POS-Teaching-and-Learning/ ListPOS-Cases.htm

Cameron, S., Dutton, J., \& Quinn, R. (2003). Positive organisational scholarship: Foundations of a new discipline. San Francisco, CA: Berrett-Koehler Publishers.

Chan, D.W. (2013). Subjective well-being of Hong Kong Chinese teachers: The contribution of gratitude, forgiveness, and the orientations to happiness. Teaching and Teacher Education, 32, 22-30. http://dx.doi.org/10.1016/j.tate. 2012.12.005

Crawford, E.R, LePine, J.A., \& Rich, B.L. (2010). Linking job demands and resources to employee engagement and burnout: A theoretical extension and meta-analytic test. Journal of Applied Psychology, 95(5), 834-848. http://dx.doi.org/10.1037/ test. Journal

De Bruin, G.P., \& Henn, C.M. (2013). Dimensionality of the 9-item Utrecht Work Engagement Scale (UWES-9). Psychological Reports, 112(3), 788-799. http:// dx.doi.org/10.2466/01.03.PRO.112.3.788-799

Deci, E.L., \& Ryan, R.M. (1985). Intrinsic motivation and self-determination in human behaviour. New York: Plenum Press.

Deci, E.L., \& Ryan, R. M. (2008). Hedonia, eudaimonia, and well-being: An introduction Journal of Happiness Studies, 9(1), 1-11. http://dx.doi.org/10.1007/s10902-006 9018-1

Demerouti, E. (2014). Design your own job through job crafting. European Psychologist, 19(4), 237-247. http://dx.doi.org/10.1027/1016-9040/9000188

Demerouti, E., Bakker, A.B., Nachreiner, F., \& Schaufeli, W.B. (2001). The job demandsresources model of burnout. Journal of Applied Psychology, 86(3), 499-512. http://dx.doi.org/10.1037/0021-9010.86.3.499

Department of Education. (2008). Foundations for learning, assessment framework, foundation phase. Pretoria: Department of Education.

Dessler, G. (1999). How to earn your employees' commitment. Academy of Management Executive, 13(2), 58-67. Retrieved from http://www.jstor.org/ stable/4165540

Dewberry, C., \& Briner, R. (2007). Report for worklife support on the relation between wellbeing and climate in schools and pupil performance. London: Worklife Support.

Diener, E. (1984). Subjective well-being. Psychological Bulletin, 95(3), 542-575. Retrieved from http://internal.psychology.illinois.edu/ ediener/Documents/ Diener_1984.pdf

Diener, E., Lucas, R.E., \& Oishi, S. (2002). Subjective well-being: The science of happiness and life satisfaction. In C.R. Snyder \& S.J. Lopez (Eds.), Handbook of positive psychology (pp. 63-73). New York: Oxford University Press.

Diener, E., Sapyta, J.J., \& Suh, E. (1998). Subjective well-being is essential to wellbeing. Psychological Inquiry, 9(1), 33-38.
Field, L.K., \& Buitendach, J.H. (2011). Happiness, work engagement and organisational commitment of support staff at a tertiary education institution in South Africa. $S A$ Journal of Industrial Psychology, 37(1), 1-10. http://dx.doi.org/10.4102/sajip. vournal of

Frankl, V.E. (1984). Man's search for meaning. (3rd ed.). New York: Pocket Books.

Frese, M., \& Fay, D. (2001). Personal initiative: An active performance concept for work in the 21st century. Research in Organizational Behavior, 23, 133-187. http://dx.doi.org/10.1016/S0191-3085(01)23005-6

Geldenhuys, M., Łaba, K., \& Venter, C.M. (2014). Meaningful work, work engagement and organisational commitment. SA Journal of Industrial Psychology, 40(1) http://dx.doi.org/10.4102/sajip.v40i1.1098

Ghitulescu, B.E. (2006). Shaping tasks and relationships at work: Examining the antecedents and consequences of employee job crafting. Unpublished doctoral thesis, University of Pittsburgh, USA. Retrieved June 03, 2015, from http://scholar. google.co.za/scholar?hl=en\&as_sdt=0,5\&q=shaping+tasks+and+relationships+at +work\%3aexamining+the+antecedents+and+consequences+of+employee+job+c rafting

Hackman, J., \& Oldham, G. (1980). Work redesign. London: Addison-Wesley.

Henn, C., \& Barkhuizen, N. (2009). Measures of affective behaviour, adjustment, and well-being. In C. Foxcroft \& G. Roodt (Eds.), Introduction to psychological assessment in the South African context. (3rd ed., pp. 49-160). Cape Town, South Africa: Oxford University Press.

Isaksen, J. (2000). Constructing meaning despite the drudgery of repetitive work. Journal of Humanistic Psychology, 40(3), 84-107. http://dx.doi.org/10.1177/ 0022167800403008

Jackson, L.T., Rothmann, S., \& Van de Vijver, F.J. (2006). A model of work-related wellbeing for educators in South Africa. Stress and Health, 22(4), 263-274. http:// dx.doi.org/10.1002/smi.1098

Janik, M., \& Rothmann, S. (2015). Meaningful work and secondary school teachers' intention to leave. South African Journal of Education, 35(2), 1-13. http://dx.doi. org/10.15700/saje.v35n2a1008

Keyes, C.L.M., Hysom, S.J., \& Lupo, K.L. (2000). The positive organization: Leadership, legitimacy, employee well-being and the bottom line. The Psychologist-Manager Journal, 4(2), 143-153. http://dx.doi.org/10.1037/h0095888

Kubberud, V., Helland, A., \& Smith, R.L. (1999). Teachers in the South: Their development and conditions of service. LINS Report, 1999-5. Retrieved May 26, 2015, from http://www.lins.no/db/pdf/report199905.pdf

Laurence, G.A. (2010). Workaholism and expansion and contraction oriented job crafting: The moderating effects of individual and contextual factors. Unpublished doctoral dissertation, Syracuse University, Ann Arbor, MI.

Leana, C., Appelbaum, E., \& Shevchuk, I. (2009). Work process and quality of care in early childhood education: The role of job crafting. Academy of Management Journal, 52(6), 1169-1192.

Lips-Wiersma, M., \& Morris, L. (2009). Discriminating between 'meaningful work' and the 'management of meaning'. Journal of Business Ethics, 88, 491-511. http:// dx.doi.org/10.1007/s10551-009-0118-9

Lips-Wiersma, M., \& Wright, S. (2012). Measuring the meaning of meaningful work Development and validation of the comprehensive meaningful work scale (CMWS). Group \& Organization Management, 37(5), 655-685. http://dx.doi. org/10.1177/1059601112461578

Matuska, K.M., \& Christiansen, C.H. (2008). A proposed model of lifestyle balance. Journal of Occupational Science, 15(1), 9-19. http://dx.doi.org/10.1080/1442759 1.2008 .9686602

May, D.R., Gilson, R.L., \& Harter, L.M. (2004). The psychological conditions of meaningfulness, safety and availability and the engagement of the human spirit at work. Journal of Occupational and Organizational Psychology, 77(1), 11-37. $\mathrm{http}: / / \mathrm{dx}$.doi.org/10.1348/096317904322915892

McDonald, R.P. (1999). Test theory: A unified treatment. Mahwah, NJ: Lawrence Erlbaum Associates, Inc.

Meier, C. (2011). The Foundations for learning campaign: Helping hand or hurdle? South African Journal of Education, 31(4), 549-573. Retrieved June 3, 2015, from houth African Journal of Education, 31(4), 549-573. Retrieved June 3, 2015, from sci_abstract

Millsap, R.E., \& Yun-Tein, J. (2004). Assessing factorial invariance in orderedcategorical measures. Multivariate Behavioral Research, 39, 479-515. Retrieved May 26, 2015, from http://ibg.colorado.edu/cdrom2012/boomsma/ FactorAnalysis/PracticalMeasurementInvarianceOrdinal/Literature/ FactorAnalysis/Pr
Millsap2004.pdf

Modisaotsile, B.M. (2012). The failing standard of basic education in South Africa. Africa Institute of South Africa, 72. Retrieved June 3, 2015, from http://scholar. google.co.za/scholar?start=20\&q=the+importance+of+education+in+south+afric google.co.za/scholar
a\&hl=en\&as sdt $=0,5$

Mullis, V.S., Martin, M.O., Kennedy, A.M., \& Foy, P. (2007). PIRLS 2006 International Report. Boston: TIMSS \& PIRLS International Study Center.

Muthén, L.K., \& Muthén, B.O. (2010). Mplus: Statistical analysis with latent variables user's guide 6.0. Los Angeles, CA: Author.

Netemeyer, G.R., Bearden, O.W., \& Sharma, S. (2003). Scaling procedures: Issues and applications. Thousand Oaks, CA: Sage.

Olivier, A.L., \& Rothmann, S. (2007). Antecedents of work engagement in a multinational oil company. SA Journal of Industrial Psychology, 33(3), 49-56. http://dx.doi.org/10.4102/sajip.v33i3.396

Ostroff, C. (1992). The relationship between satisfaction, attitudes and performance: An organizational Level Analysis. Journal of Applied Psychology, 77(6), 963-974. http://dx.doi.org/10.1037/0021-9010.77.6.963 
Pallant, J. (2011). SPSS survival manual: A step by step guide to data analysis using SPSS. (4th ed.). Crows Nest, NSW: Allen \& Unwin.

Petrou, P., Demerouti, E., Peeters, M.C.W., Schaufeli, W.B., \& Hetland, J. (2012) Crafting a job on a daily basis: Contextual correlates and the link to work engagement. Journal of Organizational Behaviour, 33, 1120-1141. http://dx.doi. org/10.1002/job.1783

Pillay, H.K., Goddard, R., \& Wilss, L.A. (2005). Well-being, burnout and competence: Implications for teachers. Australian Journal of Teacher Education, 30(2), 22-33. Retrieved May 26, 2015, from http://scholar.google.co.za/scholar?hl=en\&as_ $\mathrm{sdt}=0,5 \& \mathrm{q}=$ teachers+well+being

Pretsch, J., Flunger, B., Heckmann, N., \& Schmitt, M. (2013). Done in 60 s? Inferring teachers' subjective well-being from thin slices of nonverbal behavior. Socia Psychology of Education, 16(3), 421-434. http://dx.doi.org/10.1007/s11218-0139223-9

R Core Team. (2013). R: A language and environment for statistical computing. (Computer software package). Retrieved August 11, 2015, from http://www.r project.org/

Republic of South Africa. (2014). Employment Equity Act of 1998, Act No 55 of 1998 as amended in 2014. Pretoria, South Africa: Government Printer.

Revelle, W. (2015). Psych: Procedures for personality and psychological research Evanston, IL: Northwestern University. Retrieved August 11, 2015, from http:// CRAN.R-project.org/package=psychversion $=1.5 .8$

Rogers, E.W. (2001). A theoretical look at firm performance in high technology organisations: What does existing theory tell us? Journal of High Technology organisations: What does existing theory tell us? Journal of High Technology
Management Research, 12(1), 39-61. http://dx.doi.org/10.1016/S10478310(00)00038-9

Rothmann, S., \& Hamukang'andu, L. (2013). Callings, work role fit, psychological meaningfulness and work engagement among teachers in Zambia. South African Journal of Education, 33(2). http://dx.doi.org/10.15700/saje.v33n2a699

Saks, A.M. (2006). Antecedents and consequences of work engagement. Journal of Managerial Psychology, 21, 600-619. http://dx.doi.org/10.1108/02683940 610690169

Schaufeli, W.B., \& Bakker, A.B. (2004). Job demands, job resources and their relationship with burnout and engagement: A multi sample study. Journal of Organisational Behavior, 25, 293-315. http://dx.doi.org/10.1002/job.248

Schaufeli, W.B., Bakker, A.B., \& Salanova, M. (2006). The measurement of work engagement with a short questionnaire: A cross-national study. Educational and Psychological Measurement, 66, 701-716. http://dx.doi.org/10.1177/00131644 05282471

Schaufeli, W.B., Salanova, M., González-Romá, V., \& Bakker, A.B. (2002). The measurement of engagement and burnout: $A$ two sample confirmatory facto analytic approach. Journal of Happiness Studies, 3(1), 71-92. http://dx.doi. org/10.1023/A:1015630930326

Schreiber, J.B., Stage, F.K., King, J., Nora, A., \& Barlow, E.A. (2006). Reporting structural equation modelling and confirmatory factor analysis results: A review. The Journa of Educational Research, 99(6), 323-338. http://dx.doi.org/10.3200/JOER.99.6. 323-338

Schueller, S., \& Seligman, M. (2010). Pursuit of pleasure, engagement, and meaning: Relationships to subjective and objective measures of well-being. The Journal of Positive Psychology, 5(4), 253-263. http://dx.doi.org/10.1080/174397610037 94130

Seligman, M.E.P. (2002). Authentic happiness. New York: Free Press.
SemTools Contributors. (2015). SemTools: Useful tools for structural equation modelling. R package version 0.4-9. Retrieved August 11, 2015, from http://cran.rproject.org/package $=$ semTools

Slater, H., Davies, N. \& Burgess, S. (2009). Do teachers matter? Measuring the variation in teacher effectiveness in England. Bristol: The Centre for Market and Public Organisation.

Sosibo, L.S., \& Lomlomo, V.V. (2014). Teachers' conceptions of standards in South African Basic Education and Training: A case study. Perspectives in Education, 32(1), 73-87. Retrieved June 03, 2015, from http://search.proquest.com/openvie $w / 5 f e 5 e b a 89 f 66 d 27 e 75 b 3 b 5 e d 4 c 80 a e 1 b / 1$ ?pq-origsite=gscholar

Spreitzer, G.M. (1995). Psychological empowerment in the workplace: Dimensions, measurement, and validation. Academy of Management Journal, 38(5), 14421465. http://dx.doi.org/10.2307/256865

SPSS Inc. (2010). SPSS 18.0 for Windows. Chicago, IL: Author.

Taubman-Ben-Ari, O., \& Weintroub, A. (2008). Meaning in life and personal growth among pediatric physicians and nurses. Death Studies, 32, 621-645.

Tims, M., Bakker, A.B., \& Derks, D. (2012). Development and validation of the job crafting scale. Journal of Vocational Behavior, 80, 173-186. http://dx.doi. org $/ 10.1177 / 1059601112461578$

Tims, M., Bakker, A.B., \& Derks, D. (2014). Daily job crafting and the self-efficacyperformance relationship. Journal of Managerial Psychology, 29(5), 490-507. http://dx.doi.org/10.1108/JMP-05-2012-0148

Tims, M., Bakker, A.B., \& Derks, D. (2013). The impact of job crafting on job demands, job resources, and well-being. Journal of Occupational Health Psychology, 18(2), 230-240. http://dx.doi.org/10.1037/a0032141

Tims, M., \& Bakker, A.B. (2010). Job crafting: Towards a new model of individual job redesign. SA Journal of Industrial Psychology, 36(2), 9. http://dx.doi.org/10.4102/ sajip.v36i2.841

Vazi, M.L., Ruiter, R.A., Van den Borne, B., Martin, G., Dumont, K., \& Reddy, P.S. (2013) The relationship between wellbeing indicators and teacher psychological stress in Eastern Cape public schools in South Africa. SA Journal of Industrial Psychology, 39(1), 10. Retrieved June 3, 2015, from http://sajip.co.za/index.php/sajip/article/view/1042

Warr, P., \& Clapperton, G. (2010). The joy of work? Jobs, happiness, and you. London Routledge-Taylor \& Francis Group.

Wolhuter, C.C. (2014). Weaknesses of South African education in the mirror image of international educational development. South African Journal of Education, 34(2) 1-25. Retrieved June 03, 2015, from http://www.scielo.org.za/scielo.php?pid=SO $25601002014000200005 \&$ script $=$ sci

Wolhuter, C., Van der Walt, H., Potgieter, F., Meyer, L., \& Mamiala, T. (2012). What inspires South African student teachers for their future profession? South African Journal of Education, 32(2), 178-190. Retrieved June 03, 2015, from http://www. scielo.org.za/pdf/saje/v32n2/05.pdf

World Economic Forum. (2014). The Global Competitiveness Report (2014-2015). Switzerland, Geneva: World Economic Forum.

Wrzesniewski, A., Berg, J.M., \& Dutton, J.E. (2010). Turn the job you have into the job you want. Harvard Business Review, 88(6), 114-117.

Wrzesniewski, A., \& Dutton, J.E. (2001). Crafting a job: Revisioning employees as active crafters of their work. Academy of Management Review, 26, 179-201. http://dx.doi.org/10.5465/AMR.2001.4378011

Yves, R. (2012). Lavaan: An R package for structural equation modelling. Journal of Statistical Software, 48(2), 1-36. 